\title{
Truth-telling and the Asymmetry of the Attitude to Truth-telling to Dying Patients in Latvia
}

\author{
Ivars Neiders, Vija Sile, Vents Silis \\ Department of Humanities, Riga Stradins University
}

This article deals with concerns related to truth-telling in interaction between the doctor and the dying patient, exploring such issues as conflicting duties of veracity and non-maleficence, truthfulness and deception, and reasons behind physicians' decisions either to withhold or to disclose information about patients' diagnoses and prognoses. It focuses on various attitudes to truth-telling to dying patients, such as symmetry and asymmetry, both of which can be positive and negative. The empirical part of the article reports on the methods and results of the qualitative study carried out in Latvia during the summer of 2012. This study was based on the assessment of three case scenarios from the quantitative instrument designed by Dalla-Vorgia et al. in 1992. By means of semi-structured and focus-group interviews, evidence was gathered about physicians' and medical students' attitudes towards truth-telling, which allows the drawing of conclusions about the presence of asymmetry and symmetry in both cases. Additionally, an insight about the standards used for making decisions in case scenarios was gained and the origins of these standards were explored, revealing the aftermath of a gradual evolution from the ethics of the Soviet era to modern standards of medical ethics.

Keywords: truth-telling truthfulness, physicians, students, dying patients

\section{Introduction}

It is difficult nowadays to avoid being shocked to discover that the virtue of sincerity in physician-patient relationship was neglected in almost all ethical codes until the middle of the 2 oth Century. Neither the Hippocratic Oath nor any other important document in the long tradition of medical history

Corresponding author's address: Ivars Neiders, Department of Humanities, Riga Stradins University, Dzirciema 16, Riga, LV-1007, Latvia. Email: ivars.neiders@rsu.lv. 
pays any attention to this virtue. ${ }^{1}$ It was not that long ago (in 1927) when Joseph Collins claimed that "every physician should cultivate lying as a fine art" (Collins 2006, 607). However, a little more than six decades later, the authors of arguably one of the most influential monographs in contemporary bioethics felt justified in making the following diagnosis:

By contrast to this traditional disregard of veracity, virtues of candor and truthfulness are among the most widely praised character traits of health professionals in contemporary biomedical ethics. (Beauchamp and Childress 1994, 397)

It has been pointed out by many authors (e.g. Veatch 1989) that the most important changes in physicians' attitudes toward truth-telling took place during the 1970 s when-according to surveys conducted-more and more doctors became aware that important details about diagnosis and prognosis should be disclosed to patients. In a way, this can be interpreted as a reaction to the feeling shared by a majority of patients that they have the right to know their condition. ${ }^{2}$ But, without doubt, it is more likely that there is more than one reason for this paradigm shift. Beauchamp and Childress $(1994,398)$ mention at least seven different factors that caused the change of attitude towards disclosure: (1) more treatment options for cancer became available; development of treatment of cancer (2) improved rates of survival from some forms of cancer; this in turn (3) altered societal attitudes about cancer; ${ }^{3}$ moreover (4) attention to patient's rights has considerably increased, and (5) fear of malpractice suits grew accordingly; at the same time (6) physicians started to recognize communication as an effective means of enhancing the patient's understanding and compliance; finally, ( 7 ) medicine has increasingly become a collective enterprise and relevant information must be shared with other members of teams in hospitals. To this we would like to add that nowadays when information of varying quality and of different levels of complexity is abundantly available from different sources on the internet, the majority of patients have the possibility to gather the rel-

1 In fairness, there have been exceptions. For example, S. Bok $(1999,224)$ refers to the Jewish physician Amatus Lusitanus (1511-1568) as one of the few who made a strong appeal to the principle of honesty. One of the earliest and most prominent defenses of honesty in medical practice was made by C. Cobat in his essay "The Use of Truth and Falsehood in Medicine: An Experimental Study," published in 1909 (See Katz 1984, 25). For a valuable and short account of the history of physicians' attitudes to truth-telling, see (Katz 1984, 1-29).

${ }^{2}$ For references to the relevant surveys, see (Veatch 1989, 182-185). See also (Tuckett 2004, 501-502).

3 However, the myths surrounding cancer that were so vividly described more than three decades ago by S. Sontag (1990) are far from dead. 
evant data by themselves. As a consequence, physicians' ability to keep their patients in the dark about their condition has radically diminished.

In general, there seems to be a widespread consensus that, all things being equal, it is a physician's duty to tell the truth to their patients, even in cases where the news is very bad. This attitude hardly needs any defense nowadays. However, one may ask to what degree this phenomenon applies to non-Western or Eastern European countries. The evidence provided in many studies suggests that in other cultures the attitudes to truth-telling can be considerably different. For example, one study (Shahidi et al. 2007) conducted in Iran showed that most caregivers in the country are opposed to disclosure to their cancer patients. In Japan, most cancer patients are not told about their diagnosis (Tuckett 2004, 503). Dalla-Vorgia et al. report that Greek doctors "do not feel obliged to disclose the truth in the same way as American or British doctors" in any case, they often assume that patients do not really want to know the truth (Dalla-Vorgia et al. 1992, 70). In China, silence surrounds terminal illness and diagnostic disclosure is the family's responsibility (Tuckett 2004, 503). A similar practice is quite common in Turkey as well (Nuket 2003). Such examples from non-Western countries can be easily multiplied. ${ }^{4}$ On the other hand, some have suggested that the situation is far from static and the number of physicians advocating openness is gradually increasing (Shahidi 2010, 590).

One of the most powerful arguments used by the defenders of disclosure is the existing discrepancy between physicians' and patients' attitudes, i.e., a number of empirical studies indicate that in spite of the fact that many physicians assume that patients generally do not want to learn the sad truth about their condition, most patients express the desire to know news even if it is bad. ${ }^{5}$ Moreover, what is paradoxical in the case of physicians is a sort of double standard in their attitude toward truth-telling, i.e., on the one hand, most medical professionals say that they would not speak openly to their patients, but, on the other hand, they themselves would wish to be told the truth. ${ }^{6}$ We call this the asymmetry of the attitude to truth-telling (AATT). We think that this phenomenon is of particular interest as it is a spectacular application of double standards and, provided that it exists, its occurrence

${ }^{4}$ See references in (Shahidi et al. 2007, 216) and (Shahidi 2010, 589-590) and the discussion of (Jotkowitz et al. 2006).

5 See (Veatch 1989, 183).

6 This phenomenon was particularly emphasized by Higgs (2006, 614; originally published in 1985). Although Higgs does not mention any study that supports his statement, the evidence is not hard to find. See, for example, (Sullivan et al. 2001). Nevertheless, how widespread this phenomenon is is far from clear, as there is data which suggests the opposite. Spiro and Mandell $(1998,153)$ have observed that when physicians turn ill, they themselves prefer to be treated in paternalistic fashion. 
may be considerably diminished just by pointing it out.

The default modus operandi of Soviet health care professionals was paternalism; patients' role in decision making was rather limited and cancer patients were usually kept in the dark about their condition. Many doctors now working in Latvia's health care system received their degrees when Latvia was part of the Soviet Union and it is not unreasonable to suppose that, in spite of the official view that paternalism should be abandoned, it is quite widespread among health care professionals. But this is, as yet, only a guess, since there is no evidence that would support such a claim. From the legal point of view, patients should receive relevant information about their condition and make choices that are informed. According to the "Law on the rights of patients" (Section 6.1):

Medical treatment is permissible if a patient has given the informed consent thereto. The patient has the right to ask questions and receive answers prior to giving the informed consent.

The law particularly stresses patients' rights to receive information about their diagnosis and prognosis and other relevant aspects regarding their condition (Section 4.3):

A patient has the right to receive information regarding his or her state of health from the attending physician, including regarding the diagnosis, the plan for medical treatment, examination and rehabilitation of the disease, the prognosis and consequences, the functional restrictions caused by the disease and the opportunities for prophylaxis, as well as the right to receive information after examinations and surgical or other type of invasive intervention performed within the framework of medical treatment regarding the results of the medical treatment, regarding the previously unforeseen outcomes and the reasons thereof. (Emphasis added)

It is admitted in the law (Section 4.7) that, although patients have rights to this information, there may be conditions under which this right can be left unfulfilled, i.e., if a physician has "information or facts" that indicate that the disclosure of clinical knowledge can significantly threaten "the life or health of the patient or other persons".

Unfortunately, there are no guidelines about how the law should be applied in particular types of cases. Therefore, every physician is free to interpret the requirements according to his or her subjective understanding of which "information or facts" should be considered as life or health threatening. The requirement of protection of the interests of unspecified "other persons" is even more confusing. What could the nature of a physician's relationship to some third party be, such that it would override his or her primary duties toward the patient? And why should the patient's right to know 
the truth be ignored in favour of some other person's right not to know it? All these ambiguities leave a lot of space for a variety of practices, which result in gross irregularities in the provision of essential health care.

The fact that medical students do not receive any formal training in making such decisions does not help, either. Moreover, the "Ethical Code of Latvian Physicians" adopted by the Society of Latvian Physicians in 1995 is rather wanting in this regard. There is only one sentence that may refer to the issue under consideration, of which the proper meaning is far from clear. In the section "Responsibility to the Profession and Other Health Care Professionals" (and not in the section entitled "Physicians responsibility to patients", as one naturally might think) it is said that: "Profession demands physicians to be honest to their patients". What exactly the nature of this demand is left unclear. As a consequence, it is very hard to tell what kind of policy of disclosure patients can expect from their physicians and how physicians should make their decisions about disclosure, i.e., whether or not cancer patients should be informed about their diagnosis and prognosis, how much information should be disclosed, and how reasoning about particular cases should be conducted.

In our research, we try to minimize the informational vacuum that surrounds the practice of patient-physician communication in Latvia. Our primary aim is to gain some insight into the current attitudes of Latvian physicians to truth-telling. We intend to explore the views of practicing physicians, the information they disclose to cancer patients, the standards they apply in order to decide whether cancer patients should be informed or not, how much information patients need, whether or not patients' relatives should be involved, etc. In particular, we want to investigate the presence of AATT. Additionally, it seems useful and interesting to us to compare the attitudes of physicians to those of medical students, as the latter have not been exposed to the paternalism which was prevalent in the Soviet era.

\section{Some remarks on the concepts of this study}

Before we turn to the methods and the results of our research, we would like to comment on the concepts that we use. We have already introduced the concept of AATT. It is obvious that if there is asymmetry of the attitude to truth-telling, then there must be symmetry also (SATT). In fact, it is useful to distinguish two different kinds of SATT. If a person A believes that he or she must tell the truth in a particular context, and at the same time he or she wants to receive the same treatment from others, we call this positive SATT. If, on the other hand, a person A believes that he or she may not tell the truth in a particular situation, and he or she in a relevantly similar situation prefers not to be told as well, then we call this negative SATT. In a 
similar vein, a distinction can be drawn between two types of AATT. Positive asymmetry would be a case where a doctor is not completely truthful to patients, yet wishes to receive the whole truth in the same position. Negative asymmetry, by contrast, would involve disclosure of information to patients, while wishing not to be informed in one's own case. The existence of negative asymmetry was confirmed during the research.

\begin{tabular}{|l|l|l|}
\hline & $\begin{array}{l}\text { Doctor wants } \\
\text { disclosure if taken } \\
\text { terminally ill }\end{array}$ & $\begin{array}{l}\text { Doctor wants } \\
\text { non-disclosure if taken } \\
\text { terminally ill }\end{array}$ \\
\hline $\begin{array}{l}\text { Disclosure by } \\
\text { doctor to patients }\end{array}$ & Positive SATT & Negative AATT \\
\hline $\begin{array}{l}\text { Non-disclosure by } \\
\text { doctor to patients }\end{array}$ & Positive AATT & Negative SATT \\
\hline
\end{tabular}

Table 1. Demonstration of symmetry and asymmetry of doctors' attitudes toward truth-telling in serious clinical situations. Personal wants of the doctor should he be taken seriously ill regarding disclosure or non-disclosure of the clinical situation are set against the clinical practice of the doctor when he or she is dealing with similar situations in his or her patients. This table demonstrates the meaning of concepts used in this paper. SATT implies freedom from duplicity whereas AATT implies duplicity.

The subject of our study is truth-telling. However, we cannot resist noting that in a way the term is a misnomer. For, firstly, as already noted by Sissela Bok $(1999,6,227)$, in this particular context it is truthfulness and not truth that is at stake, i.e., the subject of our discussion is not the concept of truth but the virtue of truthfulness or, to be more specific, sincerity, a virtue that, according to Bernard Williams, is constituted by trustworthiness in speech (Williams 2002, 94). Secondly, if the opposite of truth-telling is lying, then it should be stressed that lying is not the only way in which a physician may fail to act according to the demands of the virtue of sincerity. Let us assume that a lie is:

An assertion, the content of which the speaker believes to be false, which is made with the intention to deceive the hearer with respect to that content. (Williams 2002, 96)

Now, it is clear, that in order to deceive somebody it is not necessary that the speaker makes an assertion that he or she believes to be false. A true as-

7 It may be argued that this definition has many problems, but this is not relevant to the point we want to make here. For a recent discussion of the concept of lying, see (Carson 2010, Ch. 1). 
sertion can do the job as well. ${ }^{8}$ It may be true that most cases of lying are cases of attempted deception, but it is certainly true that not all cases of attempted deception or cases of [actual?] deception are cases of lying. ${ }^{9}$ Moreover, it is not only lying and deception that we should concern ourselves with in physician-patient relationships. In this context, saying nothing and keeping patients in the dark about their diagnoses and prognoses may be no less objectionable. ${ }^{10}$ To withhold information to which patients have a right may be as wrong as lying to them or deceiving them. Of course, some of these practices are arguably worse than others, but, again, whatever position one accepts makes no difference for our purposes. We merely want to point out that when we discuss truth-telling, we have in mind issues that surround the virtue of sincerity in the physician-patient relationship, not just truth-telling narrowly understood, i.e., as making assertions that the speaker believes to be true.

\section{Methods}

Two populations were examined in our study: medical professionals and medical students. Participation was anonymous and completely voluntary. When sampling medical professionals, we chose a variety of gradual sampling strategy known as the stratified purposeful sample, which aims to: "capture major variations rather than to identify a common core, although the latter may also emerge in the analysis" (Patton 1990, 174). This strategy allows for the collection of both typical and atypical cases, encompassing the spectrum almost as comprehensively as a full maximum variation sample. Moreover, in the face of such difficulties as the absence of funding and limited time and personnel, this is one of the most optimal research strategies.

Participants were distinguished according to their speciality, gender, years of experience and place of residence (capital or other city). At the present moment, the number of medical professionals participating in the study is ten $(\mathrm{n}=10)$.

\begin{tabular}{|l|l|l|l|}
\hline Speciality & Gender & Experience (years) & Place of residence \\
\hline $\begin{array}{l}\text { Anaesthesiologist- } \\
\text { reanimatologist }\end{array}$ & female & $10-15$ & capital city \\
\hline General practitioner & female & $25-30$ & small city \\
\hline $\begin{array}{l}\text { Oncologist- } \\
\text { chemotherapist }\end{array}$ & female & $25-30$ & capital city \\
\hline General practitioner & female & $25-30$ & small city \\
\hline
\end{tabular}

${ }^{8}$ For an excellent discussion of this topic, see (Williams 2002, 100-110).

9 Cf. (Carson 2010, 56.).

${ }^{10}$ This problem was famously raised by Katz (1984). 
62 Truth-telling and the Asymmetry of the Attitude to Truth-telling to Dying Patients

\begin{tabular}{|l|l|l|l|}
\hline Speciality & Gender & Experience (years) & Place of residence \\
\hline General practitioner & female & $30-35$ & small city \\
\hline Thoracic surgeon & male & $\mathbf{2 0}-25$ & capital city \\
\hline Thoracic surgeon & male & $\mathbf{2 0}-\mathbf{2 5}$ & capital city \\
\hline Oncologist & male & $\mathbf{2 0}-\mathbf{2 5}$ & capital city \\
\hline Oncologist & male & $\mathbf{2 0}-\mathbf{2 5}$ & small city \\
\hline Neurosurgeon & male & $\mathbf{2 5}-30$ & capital city \\
\hline
\end{tabular}

Table 1. Sample description of the medical professional population. ${ }^{11}$

Our research is still a work in progress, so the sample size of medical professionals is expected to grow. However, the spectrum of views regarding truth-telling, as well as the presence and origins of asymmetry of the attitude to truth-telling, has emerged clearly enough to be worth publishing.

The method of gathering the data about the practices of medical professionals was qualitative, semi-structured interviews, which took place from May to August 2012. The length of interviews was between 30 minutes and 1 hour. Some interviews were taken in discreet settings, such as university study rooms and doctor's offices, while others were given in less discreet places, such as public cafeterias. Since the choice of location was left to the subjects themselves, we have no reason to believe that this affected the quality of data in any negative way.

Another data-gathering method was focus group interviews, employed in order to gather data about medical students' attitudes towards truth-telling and related issues in the first and second year of their studies. This method is "most useful for getting at a complex underlying notion in a setting where the sharing of experiences can help guide the other participants to greater awareness..." (Shank 2002, 48). No changes were made regarding the interview questions: the students were asked to assess the same three scenarios and to answer the same additional questions as the medical professionals. Three such group interviews were carried out and the total number of subjects was twenty three $(n=23)$.

\begin{tabular}{|l|l|l|l|}
\hline Medical students & Number and gender & Study year & Date of interview \\
\hline Group 1 & $\mathrm{n}=7(\mathrm{female}=5)$ & 1st & 29 May 2012 \\
\hline Group 2 & $\mathrm{n}=7(\mathrm{female}=6)$ & 2nd & 30 May 2012 \\
\hline Group 3 & $\mathrm{n}=9(\mathrm{female}=6)$ & 2nd & 4 June 2012 \\
\hline
\end{tabular}

${ }^{11}$ For the sake of anonymity, the subjects will not be identified by either of these characteristics in the text; numbers will be used instead, with no relation to the order depicted in this table. The only exception will be the subject's speciality, which will be mentioned only to provide necessary context. 
Table 2. Sample description of the student population.

Questions for the semi-structured interviews and focus-group interviews were composed by borrowing the three case scenarios from the quantitative research tool (a questionnaire) developed by Dalla-Vorgia et al. (1992). They took the following form:

1. Do you believe that when someone is seriously ill and it is certain (almost 100\%) that they will die soon (for example in 2-3 months) the doctor should tell them the truth?

2. Do you believe that when someone is seriously ill and it is very probable (for example 50\%) that they will die, but not very soon (for example in 5 years) the doctor should tell them the truth?

3. Do you believe that when someone is seriously ill and has a relatively low probability (for example 10\%) of dying, the doctor should tell them the truth?

In addition to this, we also asked several additional questions to help clarify the reasoning behind the answers given in the aforementioned scenarios, starting with a question addressing potential AATT:

1. If you were to assume the role of the patient in the described situations, what would you like the doctor to do?

2. What would you do if the patient did not ask any questions? Would this mean that they did not wish to know?

3. Are there any factors (such as age, gender, nationality or education) that would determine how much and what the patients wish to know?

4. What has shaped your opinion about how to deal with such situations: a study course, the example of a colleague (both positive and negative), your own experience?

\section{Results}

As Table 3 (found in the appendix at the end of the article) indicates, four of the research subjects advocated the position of either complete or partial non-disclosure of truth, while six advocated more or less complete disclosure (with exceptions in certain cases). 
Assessing the first case, where the terminal outcome was nearly $100 \%$ certain and the expected lifespan was just a few months, medical professionals were in agreement that, before giving the diagnosis, the patient's psychological condition should be evaluated in order to determine how much information they are ready to receive and how it should be delivered to them. Similar agreement emerged about the utmost care in announcing the prognosis to the patients and their families. The differences appeared on the issue of how doctors should balance their duty to tell the truth (veracity) with their obligation to do no harm (non-maleficence). The table displays a wide variety of attitudes ranging from a willingness to disclose as much as the patient wishes to deliberate attempts to avoid revealing the truth to the patient.

Responses given by the students revealed many similarities to those of the medical professionals. Assessing the first case, the students stressed the need to disclose the diagnosis, often emphasizing a careful, emphatic way of breaking the news. Regarding prognosis, the students split into two factions: one thought that patients should be informed about the severity of their condition, but not about the average lifespan of 2-3 months, doubting the precision of prognosis and expressing concerns about the likelihood of psychological damage; the other faction thought that patients must be informed about time too, in order to be able to spend their last days as they see fit. There were notable differences between the groups: in Group 2, the dominant view was that expectancy should not be revealed, while in Groups 1 and 3 , greater support was given to the opposite opinion.

Assessing the second case, where the risk of death was decreased to $50 \%$ and the average lifespan increased to 5 years, the contrast between the attitudes towards truth-telling decreased as well. A cautious attitude towards making a prognosis remained because of the higher degree of uncertainty, which increases the possibility of making a mistake. On the other hand, several doctors admitted that to deliver such news is less emotionally demanding because they are able to influence the patient's situation and apply their medical skills and knowledge. It also allows them to maintain optimism and reasonable hope: “... it is a little bit easier for the doctor to announce such news to the patient. I feel better. For me, it is terrible to accept that patient is really going to die it cannot be helped and is going to happen soon. (...) Yes, the patient may have cancer, but cancer is curable-we put more emphasis on the bright side" (S9). Others, on the contrary, saw the situation as less favorable than in the first case.

The students' opinion was less varied: they generally agreed that the diagnosis should be given. To keep up the patient's motivation and strength to fight the disease, doctors should express all possible optimism and hope, emphasizing the possibility of either recovery or the possible ways of extending 
the limits of the prognostic lifespan. To achieve this goal, some thought that instead of clearly announcing the diagnosis, which might cause unnecessary shock and distress, doctors should somehow "explain the severity of the condition" without actually mentioning the risk of dying, and then proceed to discuss treatment options, appropriate lifestyle changes and regular checkups. Others argued that things should be called by their proper names and that obscure language is inappropriate because in the long run it is counterproductive; it is possible that the patient will fail to understand the risks and, as a consequence, will not appreciate the need for check-ups and treatment.

There was also disagreement among the students about whether the 50\% risk of dying and the average 5 year lifespan should be mentioned. Some thought that the "numbers" are too relative to be of any use, and that mentioning them is likely to do more harm than good. Others disagreed, arguing that it is essential for the patient to understand the risks and to be able to make autonomous and informed decisions.

Assessing the third case, where the risk of death has shrunk to just $10 \%$ and there are no limitations for lifespan, the attitudes towards truth-telling, surprisingly, became more diverse again. Supporters of partial or complete non-disclosure argued that the risks are comparable to those that any normal person faces in their everyday lives, thus there is no need to upset the patients by mentioning the possibility of a terminal outcome. This is a surprising view that may be caused by the weak understanding of probability of the respondents, as $10 \%$ should be considered a rather high risk that is well above that we face in our everyday lives. ${ }^{12}$

The students' view of the third case was rather similar to that expressed by the medical professionals. The students also focused on whether or not a $10 \%$ risk is worth mentioning to the patient and what the justification for either doing or not doing so would be. Some viewed this risk of death as similar to the everyday risk of an average person associated with unfortunate accidents. Thus, to avoid unnecessary stress, they would not inform the patient, at the same time trying to persuade the patient to perform regular check-ups and pursue a healthy lifestyle. The opposite party argued for complete disclosure of risks as a necessary prerequisite for successful cooperation that aims at regular monitoring of symptoms and appropriate lifestyle changes. The third faction took the middle ground, arguing that whether or not risks should be mentioned depends largely on how serious the patient's attitude is: if the patient appears careless, then the risks should be mentioned

${ }^{12}$ For comparison, according to Noordzij et al. (2010), the overall postoperative mortality rate in the Netherlands was $1.85 \%$. For their part, advocates of truth-telling stated that they often place special emphasis on the relatively small chance of dying, because they see it as a useful motivational tool to facilitate changes in a patient's lifestyle. 
to alarm them.

A certain amount of disagreement between the medical practitioners was to be expected due to differences in individual understanding of how values and principles should be applied in practice. It is even less surprising, given the obscurity of regulative documents, especially the Law on the Rights of Patients, which legitimises therapeutic privilege: the right to withhold information if there is a reason (i.e. certain "information or facts") to believe that it would cause a serious psychological threat to the patient. However, the current variety of attitudes towards truth-telling means that, within the same health care system, the standards of treatment may be radically different, making it very difficult to ensure quality and stability of the health care provided. The task of social research (including ours) is to reveal such irregularities and stress the need for addressing them on a number of levels: in education, policy-making, ethics and so forth.

Similarly to the medical professionals, the students disagreed on the issue of giving the prognosis in the first and second cases and on revealing the risks in the third case. Yet student opinions displayed much less variety, which gives reason to believe that in future the gross irregularities in the health care provided will gradually level out. On the other hand, there is no guarantee that opinions currently held by students will not change in future due to, for example, pressure from older colleagues.

Now let us turn to an examination of the issue of symmetry and asymmetry in regard to truth-telling.

\begin{tabular}{|l|l|}
\hline Type of symmetrty/asymmetry & Number of cases \\
\hline Positive SATT & 4 \\
\hline Negative SATT & 3 \\
\hline Positive AATT & 2 \\
\hline Negative AATT & 1 \\
\hline
\end{tabular}

Table 4. Presence of two types of symmetry and asymmetry of the attitude to truth-telling.

As the Table 4 shows, there are four cases of Positive SATT, where doctors advocated truth-telling and wished to be told the truth in the role of patient. There are three cases of Negative SATT, where doctors did not advocate complete veracity and did not wish to know the whole truth as patients. One physician said that he would like to know the diagnosis but, as far as the prognosis was concerned, preferred to be left in the dark. Another confessed that she prefers hope to truth, even if that means being deceived by lying.

In two cases, the presence of Positive AATT was detected. In one, the asymmetry was a matter of clarity and completeness: when informing pa- 
tients about their prognosis, the doctor admitted the possibility of some degree of ambiguity and of not mentioning some unpleasant details, but as a patient wished for absolute clarity and not to be deceived in any way (Positive AATT). In the first case, the doctor would hint about diagnosis and give a very vague prognosis. In the second case, the doctor would not reveal the whole truth. As a patient, in both cases the doctor would like to receive precise information about both diagnosis and prognosis.

In one case, the subject refused to answer the question, justifying their refusal in the following way: "it is very difficult to apply this situation to myself and to truly understand it, to really feel what people feel in such moments. When people are in such critical state, they change. As long as a doctor is a doctor, that is one case, but when doctors themselves become patients, then they are not doctors anymore-they are patients with medical education. It is a totally different perception of the world..." The same difficulty was indicated by some other subjects, but nevertheless they did specify their wishes in the role of a terminal patient. Hence, the reference to cognitive limitations does not look very convincing. In the light of this consideration, and certain biographical details, we believe that the unwillingness to discuss the cases can be interpreted as an unwillingness to be informed. Thus, we categorize this as a case of Negative AATT in which the doctor would tell the truth to the dying patient, but would not wish to know it in the role of patient.

The student population presented much less variety. An absolute majority displayed Positive SATT, while a few cases of rather mild Positive AATT were detected. No cases of Negative SATT were detected. The greatest variety was found in Group 1, where we encountered a case of Negative AATT: a person argued in favour of revealing both diagnosis and prognosis in the second and third cases and advocated a personalized approach and family involvement in the first case. Yet, when assuming the role of patient, they refused to receive any information about diagnosis or prognosis, allowing only for diagnosis in the third case.

As to the origins of their standards, doctors mostly cited their professional and personal experience (death of a family member), their study and work experience abroad, legislation and scientific documentation, locally held postgraduate courses, as well as literature and films. Almost everyone made reference to Soviet-era practices; in the next section, this issue will be discussed in more detail.

When asked about the origins of their standards, students generally cited the same range of influences as medical professionals, without, of course, the reference to Soviet-era practices. In addition to books, films and personal experiences, both in clinical settings and with dying relatives, references to 
university study courses could be traced. In most cases, these references were indirect, appearing mostly through language and argumentation, not through direct reference to a particular course in ethics or medical law.

Groups also differed in terms of the level of disclosure. In Groups 1 and 3 , the most complete forms of truth-telling were dominant, while in Group 2 more disguised and indirect ways were prevalent. However, the students also voiced well-grounded criticism of the validity of their current views: in every group interview, it was pointed out that these opinions should be considered as tentative and likely to change in the light of real-life experiences in their professional settings.

Of course, there is a risk that, upon entering practice, students will adopt the attitude of their more experienced colleagues who either do not have such education or were educated according to principles of Soviet paternalism. However, as reform in health care progresses, a growing number of currently practicing physicians are re-educated and abandon the old paternalistic practices. We believe that this tendency for positive change is reinforced by providing adequate education to the next generation of doctors.

\section{Discussion}

As Table 3 shows, it is rather difficult to reduce the thoughts of medical professionals about the case to a single, clear, unambiguous opinion. To illustrate this complexity, the table contains such specifying entries as 'diagnosis' and 'prognosis'. Giving a correct prognosis has particular relevance in the context of truth-telling. Some doctors find it difficult to reveal both kinds of information, while for others it is not as difficult to give clear information about their diagnosis as it is to announce their prognosis. The problem seems to be rooted in the fact that the level of uncertainty, which is already quite high in short-term prognoses, increases with the time span: the longer it is, the larger is the likelihood of it being wrong. ${ }^{13}$ Yet the interviewed doctors seemed to feel that, regardless of these difficulties, they are expected to be as correct about their prognoses as they are about their diagnoses. Making a mistake would not only harm the patient, who would be preparing to die on a particular day, but also undermine the health professional's reputation by making them look either incompetent or as outright deceivers who have betrayed the patient's trust by making false promises.

This uncertainty was mentioned as one of the main reasons for limiting the disclosure of information. Physicians stressed the fact that diagnosis is never $100 \%$ certain, let alone the prognosis, and that, no matter how small, there is always a chance either of a technical mistake in laboratory tests or

\footnotetext{
${ }^{13}$ Similar results are reported in many other studies. See (Hancock et al. 2007, 511).
} 
of something unpredictable happening, from sudden death to a miraculous recovery.

We detected two strategies that are used to avoid being blamed for making an incorrect prognosis. The first is to cite statistics about the average lifespan of patients with such conditions: "Statistical data... is true and it must be told" ( $\left.\mathrm{S}_{1}\right)$. The second strategy is simply to avoid making any prognosis, either by appeal to one's limited human capacities ("I say that I am not God, so I can't tell how much time he has left, but he has to take into consideration that his condition is severe. That's how it is and that's how I say it" (S8)) or by appeal to something supernatural ("I usually tell the patients that everything is in hands of a higher power, and they will live as long as they have to live[...]" (S6)). It should be pointed out that this way of talking does not imply that the physician has some strong religious beliefs. At least, there is no evidence for that in our data. It is more likely that in this case the reference to God or to supernatural forces is just a way of saying that the physician's knowledge is limited. There may be at least two reasons why a physician finds such expressions useful. Firstly, he or she may think that that the patient will understand the point if it is framed in this way. Secondly, this may be a way of escaping the burden of responsibility to disclose information. An unintentional case of not offering a prognosis may occur because of an attempt to use non-technical, simple language instead of precise numbers and percentages that might sound puzzling to the patient. Sometimes these phrases might reach such a level of generalization that they become almost empty. Here is an example: "Often people don't like the term 'relative risk' - they don't understand it. (...) They don't have a good grasp of what the percentage of risk means. And then I tell them: 'You know, most likely you would live longer if you did not have this diagnosis"' (S10).

The first thing that must be noted with regard to using uncertainty of prognosis and diagnosis as a reason for limiting disclosure of information is that it is based on a misunderstanding that has long been pointed out by many authors. ${ }^{14}$ The physicians who justify their policies in this way wrongly assume that truthfulness implies the truth, but this is not so. To be truthful does not mean to tell the truth, as in many cases our knowledgeespecially in the contexts discussed in this paper-may be radically limited. What truthfulness demands from a physician is disclosure of the relevant information that he or she possesses, where relevance is determined from the patient's point of view. However, it is hard to tell whether physicians are really confused about the demands of truthfulness or whether this is just a strategy (used intentionally or unintentionally) to find some excuse for limiting the amount of information disclosed to the patient. This interpretation

${ }^{14}$ See e.g. (Bok 1999, 227). 
may be supported by other observations suggested by our data.

Firstly, we got the impression that in the context of the cases discussed physicians applied unusually high criteria for diagnosis and prognosis. ${ }^{15} \mathrm{Of}$ course, that may be explained by the fact that in the case of terminal illness the stakes are higher than usual, and physicians must be very careful with the information that they possess. However, we are not sure that this can be used as a justification for non-disclosure, as it can be argued that for the same reason patients should be informed because, in the situation where the stakes are high, the information becomes more important from the patient's point of view. Secondly, in some cases physicians openly admitted that information about prognosis or diagnosis is used to manipulate patients. For example, an oncologist said that he uses the risk percentages in order to influence the patient's decision to undertake treatment, which is quite burdensome and accompanied with many unpleasant side effects: "there also are patients who need to be heavily persuaded, scared into treatment." From the way in which physicians (and in many ways students, as well) reacted to the cases we presented, it appears as if the epistemic standards used by physicians are adjusted in accordance with the intended use of the information. If a physician wants to change a patient's attitude toward a particular therapy or life-style, then the possible risks of this or that condition are disclosed. If, on the other hand, the information has no therapeutic use, physicians are not that eager to inform the patient and in some cases even try to escape the duty to do so. For example, a general practitioner argued that it is a task of the oncological specialist to reveal the truth: "I am careful, I am not a specialist-they are the ones who should explain it all. (...) To make a prognosis, no, that's not my task. Why would I want to take unnecessary risks and surplus responsibility? No, I don't want that." Similar evasiveness was observed regarding the use of the word "cancer". Many physicians we interviewed particularly stressed that they try to avoid mentioning it when possible. For example, a thoracic surgeon explained: "One of the things we inform the patient about is that they have a malignant tumor; we may sometimes avoid the word 'cancer', instead we say 'malignant tumor' or that we found 'bad cells' or 'malignant cells"' $\left(S_{3}\right)$. However, not all physicians subscribe to this attitude. In one case, we encountered a strategy that is completely opposite. A general practitioner expressed the view that it is (rather) essential to inform the patient that he or she has cancer, as this is the term that is more familiar to an average person.

Another reason for non-disclosure is related to the issue of manipulation, to which we just referred. This is the all too well-known argument

${ }^{15}$ It must be noted that this is just our impression which is not backed by our data. We hope to gather the relevant evidence in our future research. 
according to which the truth may harm patients, and, as non-maleficence is one of the basic principles of medical ethics, physicians may not tell the truth to the patient if there are good reasons to believe that the truth will harm them. The physicians we interviewed committed themselves to the view that the truth about a terminal condition may have a devastating effect on a patient's psychological condition: they may succumb to severe depression, thus losing the ability to enjoy the few days that are left for them, or even commit suicide. Hence, it is more important to maintain the patient's hope: "If someone is hopeless, then let them be hopeless in the documents, but in real life there must be hope! Let it be false, but there must be hope! That may be just a tiny, tiny ray of light, but still-patients must think that maybe, just maybe they will get better, maybe the miracle will happen. I am an old-school doctor, that is my opinion, and so it will remain" (S7). In a similar vein, another doctor said: "If I told him straight away, then I would kill him! If I said, 'You will live for 2-3 months and that's it', I suppose they would collapse and have no wish to fight for themselves. None at all!" (S8). A neurosurgeon referred to cases of patients committing suicide after learning the truth about their condition: "These patients are much more sensitive, in comparison to terminal patients whose time has almost run out and who are in a very bad biochemical state... There have been cases in our hospital where patients have jumped out of the window because of the depression caused by finding out the diagnosis. (...) I remember at least three to four such cases."

The force of this argument has been challenged in the literature from at least two sides. Firstly, it has been mentioned that the claim is factually untrue, i.e., the damages associated with disclosure are comparatively rare (Bok 1999, 234). ${ }^{16}$ Secondly, there are substantial benefits from being informed, for example, pain is tolerated more easily, patient-physician relationships are better, etc. (Bok 1999, 234). Whatever one makes of these considerations, we think that the practices of the physicians to whom we talked are too paternalistic. True, there is evidence that bad news in some cases may cause harm, but at the same time our data suggests that many physicians use the argument as an excuse to manipulate their patients. As can be seen from the quotations above, many physicians see information as a sort of medicine that is an integral part of treatment and, accordingly, the physician decides the timing and dosage, while the patient is mere recipient. In such a situation, the patient's point of view seems to be ignored. It must be noted, however, that not all physicians subscribe to this kind of policy. Some physicians admitted that truth may cause harm to the patient, but held that this is to be avoided not by concealment but by compassionate communication. As one physician

\footnotetext{
${ }^{16}$ See (Shahidi 2010, 590).
} 
said: "it can be stated empathetically, compassionately, in language that the patient understands, without rhetoric or medical terminology, about which he is not an expert. And my personal experience is that both patients and relatives are very grateful about being told the truth, and not beating around the bush. I should be told not in some kind of obscure way, but clearly, as it is! (...) Directly and clearly. Yes, the person will be shocked, but that is the unavoidable reaction that must be experienced." ( $\left.\mathrm{S}_{10}\right)$ One example of a cautious way of telling the truth is to make the process gradual: "I consider whether to tell him all of this in one day, or in several conversations; to split it into stages, so that the person can grasp and understand everything. But I am absolutely convinced that truth must be told" (S9).

Finally, the third reason for non-disclosure is that there are patients who just do not want to know the truth. Unfortunately, there is no data about patients in Latvia concerning their attitude towards truth-telling, but we can speculate that due to the Soviet past, Latvian patients, in comparison to patients in the USA and Western European countries, are more ready to accept the paternalistic policies of physicians. In our interviews, physicians referred to particular groups of patients who showed no interest in knowing their condition. One such group is patients with substance abuse problems. As an anaesthesiologist-reanimatologist puts it: “... a person who, in his 34 or whatever years, has drunk himself to rock bottom, reaching the lowest level of degradation. You can talk to him and tell him anything you want; he is not listening, not paying attention. He has such a severe case of liver failure that it is a miracle he does not die, but he goes home and continues drinking" (S5). Other doctors indicated that socially disadvantaged patients with low education often adopt an attitude of total indifference towards their health: "There are those who are not interested in anything. They say: 'Do what you want to do, doc. If you need to operate, just go ahead.' And I believe they are not even listening to what I tell them" (S2). In such cases, doctors expressed the feeling that their attempt to communicate the truth is bound to fail, and felt justified in not making the effort: "It is not him asking us 'Please, operate on me, doctor!", it's as if we badly wanted to operate on him. As I see it, patients with such an attitude towards health don't need to be informed." $\left(S_{3}\right)$ Whether an attempt to increase the patient's involvement in these cases would be futile is hard to tell; to do so, we would need additional evidence.

Here again the physicians' approach was not unified. Some did not even mention the need to facilitate patient autonomy, while others clearly indicated that it must be done and described their actions in this respect. One described them as a "process of negotiation" $\left(\mathrm{S}_{1}\right)$ which consists of repeated efforts to convince reluctant patients to consider the consequences and make informed decisions, especially if they involve refusing cancer treatment. Oth- 
ers talked about the necessity of explaining the nature of medical manipulations: "Cooperation with the patient is essential-he has to understand what I am doing and therefore I am trying to explain what I am going or not going to do, and why. The principal purpose of the conversation is to make him understand what is happening to him." $\left(\mathrm{S}_{4}\right)$ Still others referred to the physician's moral duties: "I have to explain that he has a cancer and I am proposing to do this or that. The duty of the doctor is to inform, of course."(S9)

We assume that paternalistic attitudes and strategies are a legacy of Soviet times. This issue arose in many interviews. Some physicians referred to past practices in order to distance themselves from them: "Yes, I have received some sort of postgraduate education-10 months in the UK, where I saw that patients are very clearly notified about their diagnosis, not as it used to be in our country some time ago. In Soviet times, when offering an oncological diagnosis was absolutely prohibited, documents were filled in with all kinds of weird diagnoses, for example, "new formation" and similar rubbish that does not even mean anything" $\left(S_{3}\right)$. Some noted that the policy of nondisclosure was openly recommended to them by their teachers in medical school. Although the majority of the physicians we interviewed distanced themselves from the paternalism of the Soviet era, some of them mentioned that there are still many physicians whose attitudes have not changed: "The truth is that a good share of the people who are working there are of quite an old age, so they act in accordance with the Soviet-era practice that requires them not to inform anybody, and they keep on living by those standards. They just tell the patient that they have to go to this room and do that thing" (S2). One of our interviewees explicitly associated their point of view with paternalistic attitudes of the past, in spite of the fact that they were quite aware that those practices are opposed to those that are officially embraced: "You know, this is my opinion, I am the old generation, the old-school doctor, with a basic education from the era of Soviet socialism, when these diagnoses were kept from patients a closely guarded secret. I still have this old thinking rooted deep inside of me." $\left(\mathrm{S}_{7}\right)$. So it appears that physicians' attitudes toward past practices vary a great deal.

We think that it is reasonable to assume that disclosure policies have undergone rather substantial changes during the last 20 years. We would also like to speculate that there is some correlation between the age of the doctor and their attitude towards truth-telling, i.e., physicians who started their career in the Soviet era are less open with their patients than physicians who were trained and started practicing later. At this point, however, we have no evidence to substantiate this hypothesis and this is one of the tasks of our future research. What we can say about the present state of affairs 
is that even those health care professionals who accept the new policy of disclosure in some cases are not completely free from certain paternalistic attitudes.

Part of the problem, we suggest, lies in the fact that physicians have not received a formal training in communication skills and the moral problems of truth-telling. This manifests itself in the way in which physicians talked about their disclosure policies. In describing or justifying their practices of disclosure, physicians rarely used ethical language. In one case a physician referred to the concept of honesty, explaining that: "It is honest to the patient to inform them about the existence of such a risk, that this diagnosis may lead to a fatal outcome, and the patient must be informed about it." ( $\left.\mathrm{S}_{3}\right)$. Later, they justified their practice with reference to the conception of rights: "And, of course, in this case I don't have the right to hide this from the patient." Another specialist justified their practice of disclosure by saying that it would be unethical not to tell the truth to a competent patient. In other cases, the physicians justified their practices by referring to legal considerations. For example, one of the physicians said that they do not disclose information to patients' relatives as it is against the Law on the Rights of Patients. On one occasion, our interviewee pointed out that truth-telling is a matter of the doctor's reputation. It seems that, in this regard, practicing physicians considerably differ from the medical students to whom we talked. Students in their answers more frequently used moral and legal terms to explain or justify their point of view. Many of them stressed that patients have rights to know their condition. This, of course, may be due to at least two reasons. Firstly, their thinking is relatively unaffected by the practices of the Soviet era. However, we would not say that they are completely free from this, as many of the students that participated in our discussions already have some clinical experience and have been exposed to the practices of their older colleagues. Moreover, paternalistic attitudes may have been acquired by other means as well, e.g., through the family. Secondly, all the students in our study were introduced to the terminology of rights during their first year in university, as they had a course in "Bioethics" and on "Law in Medicine". Thirdly, it is possible, of course, that the students have not become familiar with the complexity of end-of-life situations in clinical practice.

Lack of formal training may correlate with a lack of reflection about different moral priorities involved in the situations that we discussed in our interviews and the physicians' capacity to relate these situations to themselves as potential patients. This can be seen from the considerable level of asymmetry detected in our study. We also noticed that in many cases where physicians were asked about their attitudes in the role of patient, it took them more time than usual to formulate a point of view and in some cases they 
seemed to be uncertain about the view they had expressed. This is how one of them formulated their answer to the question about whether they would like to know the statistics concerning their lifespan: "I think even, that...I think, I wouldn't want. I think...yes, I wouldn't want." (S6) However, it must be added that there are exceptions. In one case, a physician described their policy with reference to the Golden Rule, stating that they would like to be treated in the same way that they treat their patients: "I'm following the principle 'Do unto others as you would have them do to you."' ( $\left.\mathrm{S}_{4}\right)$

\section{Some reservations about the method used}

We are aware of the limitations and weaknesses of the semi-structured interviewing technique, such as the problem of validity (no reliable criteria of distinguishing truth from lies), self-deception, constructive nature of human memory, and effect of social desirability. We are also aware of the difficulties of interpreting and making generalizations that are related to the highly subjective nature of the data gathered. Bearing all of this in mind, we have reason to believe that skilful interviewing (sometimes involving two interviewers at the same time), followed by careful analysis and description of the results, can help to overcome these obstacles.

Limitations and weaknesses of the group interviews are the validity, reactive effect (the feeling of being watched and studied), dominance of one or two subjects, and difficulty of analysis due to the subjective nature of data. These were compensated for by skilful moderation (sometimes involving two or even three moderators at the same time), careful analysis and description of findings.

The next step in our research would be to conduct a quantitative study among the aforementioned populations, as well as patients, in order to determine the impact of demographic factors on the issue of truth-telling in Latvia, and to detect the quantitative dimensions of attitude to the asymmetry to truth-telling.

\section{Conclusion}

To get a full picture of truth-telling policies, it would be necessary to conduct a quantitative study not only of health care professionals' attitudes, but of patients as well. In this case, we would be able to tell whether there is any discrepancy between what physicians disclose and what patients expect to hear.

Our study showed that there is no common policy of truth-telling shared by all physicians and a sort of particularism that they defined as a patientcentered approach to medicine. In practice, this may range from promotion 
of patients' autonomy and informed decision-making to various degrees of arbitrariness, occasionally even cases of paternalism. However, it is hard to tell to what degree this is caused by the fact that the attitudes may differ with the speciality of the health care professional. We think that a more unified approach to truth-telling would be more helpful for patients, as in this case they would know what to expect from the health care professional.

\section{Acknowledgments}

The first results of our study were reported on 11 June, 2012 at a seminar on "Medical philosophy and medical ethics in the Nordic and the Baltic countries-some pressing issues", held in Tartu, Estonia. We would like to thank the participants at the event for the constructive criticisms that they raised. We also wish to thank both of the anonymous reviewers for constructive feedback; their comments have helped to improve the manuscript greatly. And we would like to express our gratitude to all of the participants in the study, both doctors and medical students. This research would not have been possible without them.

\section{Bibliography}

Beauchamp, T. and Childress, J. (1994). Principles of biomedical ethics, 4th edn, Oxford University Press, Oxford.

Bok, S. (1999). Lying. Moral choice in public and private life, and edn, Vintage Books, New York.

Carson, T. (2010). Lying and deception. Theory and practice, Oxford University Press, Oxford.

Collins, J. (2006). On telling patients the truth, in H. Kuhse and P. Singer (eds), Bioethics. An Anthology, Blackwell Publishing, pp. 605-610.

Dalla-Vorgia, P., Katsouyanni, K., Garanis, T., Touloumi, G., Drogari, P. and Koutselinis, A. (1992). Attitudes of a mediterranean population to the truth-telling issue, Journal of Medical Ethics 18: 67-74.

Hancock, K., Clayton, J., Parker, S., der Wal, S., Butow, P., Carrick, S., Currow, D., Ghersi, D., Glare, P., Hagerty, R. and Tattersall, M. (2007). Truthtelling in discussing prognosis in advanced life-limiting illnesses: A systematic review, Palliative Medicine 21: 507-511.

Higgs, R. (2006). On telling patients the truth, in H. Kuhse and P. Singer (eds), Bioethics. An Anthology, Blackwell Publishing, pp. 611-617. 
Jotkowitz, A., Glick, S. and Gezundheit, B. (2006). Truth-telling in a culturally diverse world, Cancer Investigation 24: 786-789.

Katz, J. (1984). The silent world of doctor and patient, The Free Press, New York.

Noordzij, P., Poldermans, D., Schouten, O., Bax, J., Schreiner, F. and Boersma, E. (2010). Postoperative mortality in the netherlands: A population-based analysis of surgery-specific risk in adults, Anesthesiology 115: 1105-1115.

Nuket, O. (2003). Truth-telling information and communication with cancer patients in Turkey, Journal of the International Society for the History of Islamic Medicine 2: 31-36.

Patton, M. (1990). Qualitative evaluation and research methods, Sage, London.

Shahidi, J. (2010). Not telling the truth: Circumstances leading to concealment of diagnosis and prognosis from cancer patients, European Journal of Cancer Care 19: 589-593.

Shahidi, J., Taghizadeh-Kermani, A., Yahyazadeh, S., Khodabakhshi, R. and Mortazavi, S. (2007). Truth-telling to cancer patients from relatives' point of view: A multi-centre study in Iran, Austral-Asian Journal of Cancer 6: $213-217$.

Shank, G. (2002). Qualitative research: A personal skills approach, Pearson, Upper Saddle River.

Sontag, S. (1990). Illness as metaphor and AIDS and its metaphors, Picador, New York.

Spiro, H. and Mandell, H. (1998). When doctors get sick, Annals of Internal Medicine 128: 152-154.

Sullivan, J., Menapace, L. and White, R. (2001). Truth-telling and patient diagnoses, Truth-telling and patient diagnoses 27: 192-197.

Tuckett, A. (2004). Truth-telling in clinical practice and the arguments for and against: A review of literature, Nursing Ethics 11: 500-513.

Veatch, R. (1989). Death, dying and the biological revolution, Yale University Press, New Haven.

Williams, B. (2002). Truth and truthfulness, Princeton University Press, Princeton. 


\begin{tabular}{|c|c|c|c|}
\hline$N r$. & Case 1 & Case 2 & Case 3 \\
\hline Subject 1 & $\begin{array}{l}\text { It depends. (Truth.) } \\
\text { Diagnosis—-patient-centered approach } \\
\text { Prognosis_-general time }\end{array}$ & $\begin{array}{l}\text { It depends. (Truth.) } \\
\text { Diagnosis-yes } \\
\text { Prognosis-certain risks, general time }\end{array}$ & $\begin{array}{l}\text { It depends. (Truth.) } \\
\text { Diagnosis-yes } \\
\text { Prognosis-emphasizing risks, } \\
\quad \text { general time }\end{array}$ \\
\hline Subject 2 & $\begin{array}{l}\text { Truth. } \\
\text { Diagnosis-patient's psychological condition } \\
\text { Prognosis-no certainty about death and time }\end{array}$ & $\begin{array}{l}\text { Truth. } \\
\text { Diagnosis-yes } \\
\text { Prognosis—certain risks, general time }\end{array}$ & $\begin{array}{l}\text { Truth. } \\
\text { Diagnosis-yes } \\
\text { Prognosis-certain risks, general time }\end{array}$ \\
\hline Subject 3 & $\begin{array}{l}\text { It depends (Truth.) } \\
\text { Diagnosis-patient's psychological condition } \\
\text { Prognosis-general time }\end{array}$ & $\begin{array}{l}\text { Truth. } \\
\text { Diagnosis-yes } \\
\text { Prognosis-certain risks, general time }\end{array}$ & $\begin{array}{l}\text { Truth. } \\
\text { Diagnosis-yes } \\
\text { Prognosis-certain risks, general time }\end{array}$ \\
\hline Subject 4 & $\begin{array}{l}\text { It depends (Truth.) } \\
\text { Diagnosis-patient's psychological condition } \\
\text { Prognosis-general time }\end{array}$ & $\begin{array}{l}\text { Truth. } \\
\text { Diagnosis-patient's psychological condition } \\
\text { Prognosis-general time }\end{array}$ & $\begin{array}{l}\text { It depends. (Truth.) } \\
\text { Diagnosis-yes } \\
\text { Prognosis-certain risks, general time }\end{array}$ \\
\hline Subject 5 & $\begin{array}{l}\text { It depends. (No.) } \\
\text { Diagnosis-patient's psychological condition } \\
\text { Prognosis-informing relatives }\end{array}$ & $\begin{array}{l}\text { No. } \\
\text { Diagnosis-no } \\
\text { Prognosis-no }\end{array}$ & $\begin{array}{l}\text { It depends. (No.) } \\
\text { Diagnosis-informing relatives } \\
\text { Prognosis-informing relatives }\end{array}$ \\
\hline Subject 6 & $\begin{array}{l}\text { No. } \\
\text { Diagnosis-it is assumed that they already know }[\ldots] \\
\text { Prognosis—-time is uncertain }\end{array}$ & $\begin{array}{l}\text { Truth. } \\
\text { Diagnosis-yes } \\
\text { Prognosis-risks and side effects }\end{array}$ & $\begin{array}{l}\text { It depends. (Truth.) } \\
\text { Diagnosis-yes } \\
\text { Prognosis-yes }\end{array}$ \\
\hline Subject 7 & $\begin{array}{l}\text { No. } \\
\text { Diagnosis—no, avoid clarity } \\
\text { Prognosis—no, never; maybe relatives }\end{array}$ & $\begin{array}{l}\text { No. } \\
\text { Diagnosis—task of a specialist } \\
\text { Prognosis—task of a specialist }\end{array}$ & $\begin{array}{l}\text { No. } \\
\text { Diagnosis-no } \\
\text { Prognosis-no }\end{array}$ \\
\hline Subject 8 & $\begin{array}{l}\text { It depends. (Limited truth.) } \\
\text { Diagnosis-not all of the truth, just hints } \\
\text { Prognosis-general time }\end{array}$ & $\begin{array}{l}\text { It depends. (Limited truth.) } \\
\text { Diagnosis-patient's psychological condition } \\
\text { P and, complications too }\end{array}$ & $\begin{array}{l}\text { No. } \\
\text { Diagnosis-no } \\
\text { Prognosis-no }\end{array}$ \\
\hline Subject 9 & $\begin{array}{l}\text { Truth. } \\
\text { Diagnosis-patient's psychological condition } \\
\text { Prognosis_-general time }\end{array}$ & $\begin{array}{l}\text { Truth. } \\
\text { Diagnosis-yes, but carefully } \\
\text { Prognosis-yes, but prognoses are unreliable }\end{array}$ & $\begin{array}{l}\text { Truth. } \\
\text { Diagnosis-yes } \\
\text { Prognosis-yes, emphasizing risks }\end{array}$ \\
\hline Subject 10 & $\begin{array}{l}\text { Truth. } \\
\text { Diagnosis-yes, but carefully } \\
\text { Prognosis-yes, but carefully }\end{array}$ & $\begin{array}{l}\text { Truth. } \\
\text { Diagnosis-yes } \\
\text { Prognosis-yes, but carefully }\end{array}$ & $\begin{array}{l}\text { Truth. } \\
\text { Diagnosis-yes } \\
\text { Prognosis-yes, emphasizing risks }\end{array}$ \\
\hline
\end{tabular}

